\title{
Detection of Plant Disease on Leaves using Blobs Detection and Statistical Analysis
}

\author{
N. S. A. M Taujuddin ${ }^{1}$, A.I.A Mazlan², R. Ibrahim $^{3}$, S. Sari ${ }^{4}$, A. R. A Ghani ${ }^{5}$, N. Senan ${ }^{6}$, W.H.N.W Muda ${ }^{7}$ \\ Faculty of Electrical and Electronic Engineering ${ }^{1,2,4}$ \\ Faculty of Computer Science and Information Technology, \\ Faculty of Civil and Environmental Engineering ${ }^{5}$ \\ Faculty of Technical \& Vocational Education ${ }^{7}$ \\ Universiti Tun Hussein Onn Malaysia, 86400 Parit Raja, Batu Pahat, Johor, Malaysia 1, 2, 3, 4, 5, 6, 7
}

\begin{abstract}
Plant is exposed to many attacks from various micro-organism, bacterial disease and pests. The symptoms of the attacks are usually distinguished through the leaves, stem or fruit inspection. Disease that are commonly attack plants are Powdery Mildew and Leaf Blight and it may cause severe damaged if not controlled in early stages. Image processing has widely being used for identification, detection, grading and quality inspection in the agriculture field. Detection and identification disease of a plant is very important especially, in producing a high-quality fruit. Leaves of a plant can be used to determine the health status of that plant. The objective of this work is to develop a system that capable to detect and identify the type of disease based on Blobs Detection and Statistical Analysis. A total 45 sample leaves images from different colour and type were used and the accuracy is analysed. The Blobs Detection technique are used to detect the healthiness of plant leaves. While Statistical Analysis is used by calculating the Standard Deviation and Mean value to identify the type disease. Result is compared with manual inspection and it is found that the system has $86 \%$ in accuracy compared to manual detection process.
\end{abstract}

Keywords-Image processing; blob detection; edge detection; statistical analysis; disease detection

\section{INTRODUCTION}

Nowadays, image processing is widely used in agriculture, security system and medical field. Various researchers and advancements are going on vigorously in plant disease detection in the agricultural field. One of the promising applications in image processing is agriculture. Image processing can be used to identify the plant disease, grading the fruits and ripeness of the fruit [1].

Plant that are constantly attacked by disease are papaya, chili and tomato. These plants usually attacked by disease namely Powdery Mildew, Leaf Blight and Black Spot [2]. Black Spot disease is caused by Asperisporium caricae bacteria, where both leaves and fruit of the plant can be affected. This disease can affect the plant at any stages of their growth [3]. Leaf Blight is another disease appear on leaves as small and irregular scatter. It is brown to grey in colour.

The Powdery Mildew and Leaf Blight are persistent and common threat to plant. Moreover, plant is also host to a dozen species of fungal. This fungal disease of plant leaf and fruit may cause premature defoliation. Besides that, when the plant leaves and fruit affected by these fungal it may decrease the production [2].

To produce a high-quality fruit, there is a need to have a healthy tree, where the plant disease needs to be detected at early stages. Thus, in this research, a method is propose to detect the disease of a plant by using image processing technique. Consequently, it will help to increase the volume of production thus cater the demand of market.

\section{LITERATURE REVIEW}

In agriculture, the important thing to measure from the farmer's points of view are canopy, yield and quality of product. Hence, application of image processing can be used to improve the decision making for vegetarian measurement, irrigation and fruit sorting. There are some example application of image processing in agricultural field such as tree detection, counting of apple, disease detection, fruit ripeness detection and fruit quality detection.

The challenges in continual fruit cultivations is calculate the quantity of fruits on a tree because it need to get yield estimation form different farm. Circular Hough transform (CHT) and color thresholding method are used to detect and count each apple fruit. By using these method, the identification process is successfully done with fruits are clearly visible [4].

Various micro-organism and bacterial disease and pest attack on chili plant. The symptoms can be seen through the leaves, stems or fruit inspection. Leaf features inspection need to done for early detection of chili disease. Image of leaves are captured and processed to examine the healthy status of each plant. Moreover, these techniques can ensure the chemicals are only use when the plants are affected by disease. Hundreds of chili disease image are used in image processing techniques and its very useful and inexpensive system [5].

The author in [6] proposed a hybrid method to detect the fruit ripeness by using histogram matching, clustering algorithms-based image segmentation and relative value of parameter-based segmentation. The input data are colored images of fruits and vegetables. The threshold levels are set to find the maturity level of fruits and vegetables by comparing the input data images with threshold levels [6]. 
Mango is one of the commercial fruits produced and consumed throughout the world. Two method for classification of ripening stage based on changes in their visual features are proposed in [7]. The method are RGB and HSV where the ripening stage is detect based on the red, green and blue components of the image pixels while analysed for detection using HSV method the hue- saturation-value map [7].

The analysis that shows the fruits are quality are not based on their size by consumer performance, i.e. consumer prefer fruits of equal weight uniform size for example people like yellow bananas, dark red apple, light green or dark black grapes and yellow mango etc. Furthermore, the estimation mean of fruit size is important in meeting quality standard increasing marketing value monitoring growth. So that, the method was proposed to determine the quality (i.e. ripe, partial ripe, ripe or over ripe (bad fruit)) is based on appearance of color level estimation further which is image analysis, visual examination and inspections of color are included [8].

The most important things in agriculture are to have are high yield and quality product. However, disease is a huge problem that can reduce the production. Diseases that are usually occurred at early stages, are Powdery Mildew, Leaf Blight, Black Spot, Leaf Curl and Ring Spot. Detection of these disease is very necessary because if the plants are affected by the disease, the quality of fruit will be decreased, and the maturity of the fruit is interrupted. Hence, it will interrupt the production yield.

Powdery Mildew (see Fig. 1) growth in humid areas with warm days and cool nights, such as at north Kona on the island of Hawai'i. The symptoms for early stages of the disease is the undersides of leaves are speckled with small, water-soaked spots that becoming powdery patches of mycelium and spores. Hence, the infections usually concentrated near the leaf veins. Then the diameter of white patches is from 1-6 cm, with yellowish-green spots on the upper leaf surface.

Next, mildewed areas grow and will serve yellowing between the veins increasing. Furthermore, the spore-forming mycelium will wrap around the leaf edge and grow on the upper leaf surface and petioles. For the disease progress, infected leaves become necrotic and appear scorched. They curl and fall from plants prematurely. Mildew on immature fruit begins as circular patches of white mycelium and spores that can coalesce and cover the entire fruit. The deformed fruit is edible but has little or no value in the market [2].

The Leaf Blight is also known as, Leaf Spot or Black Rust (see Fig. 2). This disease is attacked to the leaves under certain conditions. Maturing fruit may affected too. Moreover, the fungus disease of Leaf Blight is caused by Puccniopsis caricae bacteria. Next, the symptoms of plant leaf blight are recognized through black pustular spots that appear on the under surfaces of infected leaves. Above the leaf tissue, the infected area is small, generally circular in outline and slightly raised above the leaf tissue.

The primary infections are usually scattered and the size one to eight of an inch to mere dots. The infections appear as a small brown spot of dead tissue on the upper side of affected leaves [9].

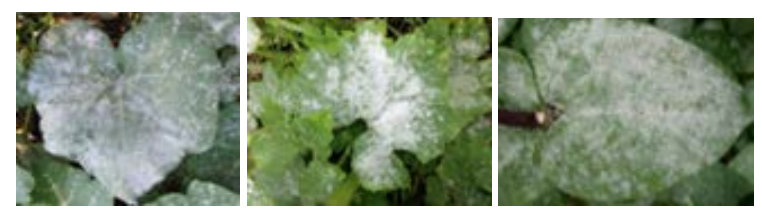

Fig. 1. Powdery Mildew on Leaves.

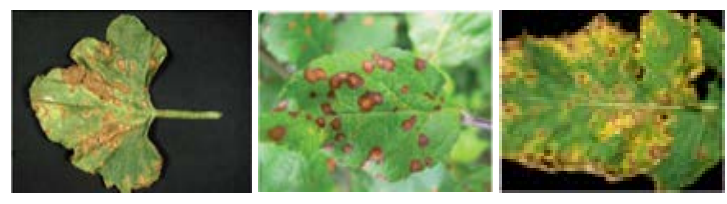

Fig. 2. Leaf Blight on Leaves.

\section{Methodology}

The process begins with image acquisition which is obtaining the image sample from various resource such as Plantix.Net website. Here, 15 sample image of healthy leaves, 15 sample images of Powdery Mildew and 15 sample images of Leaf Blight are collected. Then, pre-processing task involve some procedure to prepare the image to be ready for image processing by converting it to grey scale image. Then, the images undergoes the Blobs Detection process to identified either it is healthy or unhealthy leaves. Next, the Statistical Analysis is done, where the Standard Deviation and Mean value is calculated to classify the plant into Powdery Mildew or Leaf Blight.

Healthy leaves mean, the surfaces on leaves is clear with healthy green of color. While the unhealthy leaves have some dots coloured with white, brown or black. The input image is converted into grayscale image to detect the healthiness of leaves. This conversion is applied to transform the coloured image into black and white coloured ranged between 0 and 255. After that the value of threshold is estimated.

Here threshold value 0.45 is used. In order to perform 2-D Median filtering, the binary image need to be inverted. The grey scale image is filtered using the function of "medfilt2" which stand for 2-D median filtering. The 2-D median filtering is used to remove the noise. This is because each output pixel contains the median value in the $\mathrm{m}$-by-n neighbourhood ( $\mathrm{m}$ for row and $\mathrm{n}$ for column) around the corresponding pixel in the input image.

Next, edge detection using Canny filter technique is performed to create a boundary of contours on filtered plant leaves image. Then, contour with defective part is filled with the numerous blobs and perfect part filled with no blobs or minimum number of blobs.

Contour is used to control the image features for appearance and behaviour of objects. By using the image processing, leaves extracts the contour line information from the intensity image and the result of image was determined from contour information [10]. This statement is based on equation of contour.

$E_{\text {snake }}=\int_{0}^{1}\left[E_{\text {int }}(v(s))+E_{\text {ext }}(v(s))\right] d s$

where $v(s)$ is the parameter equation of the contour, and $s$ is the arc length. 
The Blobs Detection is a process to obtain regions of interest for further processing and these regions can detect the presence of object or parts [11]. The higher the number of blobs shows the unhealthy leaves, while the lower the number of blobs, shows the healthy leaves [10].

The statistical analysis is done by measuring the Standard Deviation and Mean value of the histogram on plant leaves [12]. Firstly, standard deviation is applied on histogram because the histogram can show the colour intensity values of colour images. Also, Standard Deviation can calculate the contrast of the colour image based on histogram. The equation to calculate the Standard Deviation is

$\operatorname{std}(i, j)=\left(\frac{1}{8} \sum_{k=1}^{8} x_{k}-l_{m}(i, j)^{2}\right)^{\frac{1}{2}}$

where $x_{k}$ are eight surrounding pixel around processing pixel $l_{m}(i, j)$ and $j$ is varies from 2 to number of rows and 2 to number of columns [13].

Then, Mean function are used to measure the average intensity value of the pixel distribution. The equation for the above statement are [12][14]:

$\mu_{m}=\sum_{n=0}^{L-1}\left(\left(x_{n}-y\right)^{m} t\left(x_{n}\right)\right)$

and

$y=\sum_{n=0}^{L-1}\left(x_{n} t\left(x_{n}\right)\right)$

The range of Standard Deviation and Mean will then be used to classify the disease either Powdery Mildew or Leaf Blight [15-16]. These measurement deals with the variation of intensity of the image surface.

\section{RESULT AND ANALYSIS}

There are several steps needed in blobs detection to identify either the leaves is healthy or not. First of all, the original image is read. Then, the original image is converted into grey scale image. This conversion is applied to transform the colour image into black and white colour. Next, the grey scale image are filtered using 2-D median filtering. Next, edge detection using Canny filter is performed to create a boundary of contours on filtered leaves image. Then, it goes to analysis where contour with defective part will be filled with the numerous blobs while perfect part is filled with no blobs or minimum number of blobs.

Contour is used to control the image features for appearance and behaviour of objects [17]. Using the image processing, leaves extracts the contour line information from the intensity image and the result of image was determined from contour information [10] [18].

The blobs detection is a process of detecting the image with different properties of brightness or color, compared to surrounding region and these regions can detect the presence of object or parts [11][19-21].

Based on the step used, the unhealthy leaves can be identified by extracting the contour of damaged part. The healthy and unhealthy leaves are categorized by the number of blobs. For image with number of blobs is equal or less than 90, it is considered are healthy leaves. While image with more than 90 blobs are considered are unhealthy leaves (refer Table I).

In this analysis, 45 leaves images are used to test the blobs appearance. From 45 images, there has 13 healthy leaves and 26 unhealthy leaves are detected.

Table II shows two example of healthy leaves. These two sample shows less than 90 blobs occurrence reflecting that the surface of the leaves are perfect and smooth with no Powdery Mildew and Leaf Blight. At the contour step, at defective part the image is filled with the numerous blobs and perfect part filled with no blobs or minimum number of blobs. Hence, the outline of image is look very clear at contour's step and it show the image has a perfect surface. Then, from the contour result, calculation number of blobs is done.

Table III shows two example of Leaf Blight image sample. The detection of the brown spot and scar has undergoes process of edge detection. There is no normal shape of the plant leaves present because the outline of the leaves is not really clear and high number of blobs are present. At contour step, the shape of the leaves is not in a good surface; it has brown spot and contains a lot of blobs. The numbers of blobs were detected more than 90 in the images and it is classified as unhealthy leaves.

TABLE I. TABle Type Styles RANGE OF LEAVES HeAltiness BASED ON NUMBER OF BLOBS

\begin{tabular}{|l|l|}
\hline Healthiness & Number of Blobs \\
\hline Healthy & $\mathrm{x} \leq 90$ \\
\hline Unhealthy & $\mathrm{x}>90$ \\
\hline
\end{tabular}

TABLE II. Blobs Detection ANALysis to Detect THE HEALty LEAVES

\begin{tabular}{|c|c|c|}
\hline Sample & Image 1 & Image 2 \\
\hline Original image & & \\
\hline Grey Scale image & & \\
\hline Binary image & & \\
\hline Filtering & & \\
\hline Edge detection & & \\
\hline Contour & 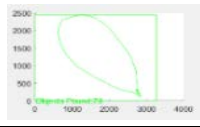 & 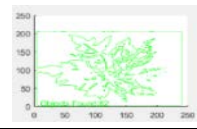 \\
\hline Number of blobs & 78 & 82 \\
\hline Decision & Healthy & Healthy \\
\hline
\end{tabular}


TABLE III. BLOBS DETECTION ANALYSIS TO DETECT THE UNHEALthy LEAVES

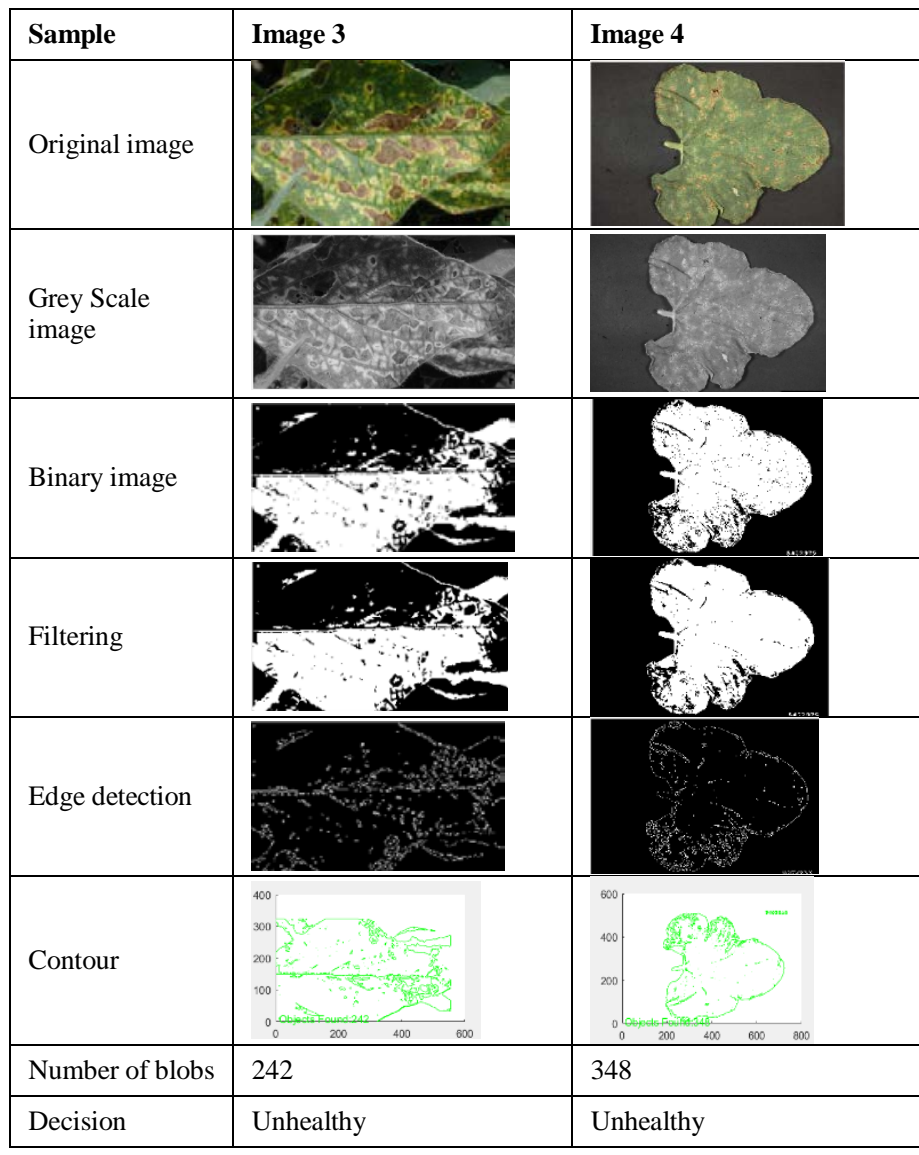

Shape of leaves and different color spotted on leaves will play an important role in identifying it as healthy or unhealthy leaves.

There are several steps in Statistical Analysis done to classify the disease either Powdery Mildew or Leaf Blight. The result from blobs detection are determined either the leaves is healthy or not. If the sample detected as unhealthy it will be proceeded to the next step which Statistical Analysis.

The Statistical Analysis is done by performing Standard Deviation and Mean value analysis. The Standard Deviation value will give a representation of the amount of variations in average while Mean value will give average intensity of all the pixels in the image representation [12]. 15 leaves with Powdery Mildew and 15 leaves with Leaf Blight are tested its Standard Deviation and Mean value. From the testing, it can be conclude that, the Powdery Mildew has the Standard Deviation ranging from 39 to 73, while Leaf Blight from 31 to 57 (see Table IV). While for Mean value, the Powdery Mildew ranging from 107 to 139, and Leaf Blight ranging from 71 to 150 (see Table V).

Tables VI and VII shows four different leaves images samples. Each of image has shown a different value of Standard Deviation and Mean. By mapping these statistic value to Tables IV and V, it lead to determination of either the leaves are effected with Powdery Mildew or Leaf Blight.
TABLE IV. STANDARD DEVIATION VALUE RANGE FOR DisEASE CLASSIFICATION

\begin{tabular}{|l|l|}
\hline Disease & Standard Deviation \\
\hline Powdery Mildew & $39 \leq \mathrm{x} \leq 73$ \\
\hline Leaf Blight & $31 \leq \mathrm{x} \leq 57$ \\
\hline
\end{tabular}

TABLE V. Mean VAlue Range For Disease Classification

\begin{tabular}{|l|l|}
\hline Disease & Mean \\
\hline Powdery Mildew & $107 \leq \mathrm{x} \leq 139$ \\
\hline Leaf Blight & $71 \leq \mathrm{x} \leq 150$ \\
\hline
\end{tabular}

TABLE VI. ANALysis on LEAVEs AfFected With PoWdery MiLdeW DISEASE

\begin{tabular}{|l|l|l|}
\hline Sample & Image 16 & Image 18 \\
\hline Original image & & \\
\hline Grey Scale image & \\
\hline Filtering & & \\
\hline Histogram graph & Powdery Mildew & $\begin{array}{l}\text { Powdery } \\
\text { Mildew }\end{array}$ \\
\hline Standard deviation & 54.39 & 53.28 \\
\hline Mean & 115.68 & \\
\hline Decision & & \\
\hline
\end{tabular}

TABLE VII. ANALysis on LeAVEs AfFected With LEAF Blight Disease

\begin{tabular}{|c|c|c|}
\hline Sample & Image 40 & Image 42 \\
\hline \multicolumn{3}{|l|}{ Original image } \\
\hline \multicolumn{3}{|l|}{ Grey Scale image } \\
\hline \multicolumn{3}{|l|}{ Filtering } \\
\hline \multicolumn{3}{|l|}{ Histogram graph } \\
\hline Standard deviation & 56.48 & 32.42 \\
\hline Mean & 100.01 & 127.44 \\
\hline Decision & Leaf Blight & Leaf Blight \\
\hline
\end{tabular}




\section{CONCLUSION}

In this research, a system to overcome the problems of manual inspection and classifying the disease of leaves is completely done. This system used blobs detection and calculation of statistical analysis to classify the disease either Powdery Mildew or Leaf Blight. Forty-five images from different categories were used. Result are compared with manual results and it is found that it was $86 \%$ accurate in this system.

\section{ACKNOWLEDGMENT}

The authors would like to thank the Universiti Tun Hussein Onn Malaysia (UTHM), Research, Innovation, Commercialization and Consultancy Management (ORICC) office and Malaysian Ministry of Education for facilitating this research activity under Multi Disciplinary Research (MDR) Grant Vote H485.

\section{REFERENCES}

[1] P. Soni, "Identification of Plant Disease Using Image Processing Techniques,” Int. J. Res. Med. \&Applied Sci., vol. 1, no. 5, pp. 1-4, 2015.

[2] B. Cunningham and S. Nelson, "Powdery Mildew of Papaya in Hawaii," Plant Dis., no. July, pp. 1-4, 2012.

[3] A. Caricae, S. Maubl, and S. Pal, "Studies on Black Spot of Papaya (Carica papaya L.), 2012.

[4] K.Behera, Santi \& Mishra, Namrata \& Sethy, Prabira \& Rath, Amiya. (2018). On-Tree Detection and Counting of Apple Using Color Thresholding and CHT. 0224-0228. 10.1109/ICCSP.2018.8524363.

[5] H.Zulkifli, A.Hallis, A.Yeon and Rohani, "Feasibility Study on Plant Chili Disease Detection Using Image Processing Techniques,” 2012 International Conference on Intelligent Systems Modelling and Simulation ., no. c, pp. 291-296, 2012.

[6] M.Dadwal and V. K. Banga, "Color Image Segmentation for Fruit Ripeness Detection: A Review," 2nd International Conference on Electrical, Electronic and Civil Engineering (ICEECE'2012)., no. c, pp. 190-193, 2012.

[7] R.P.Salunkhel and A.A.Patil, "Image Processing for Mango Ripening Stage Detection: RGB and HSV method," 2015 Third International Conference on Image Infonnation Processing., no. c, pp. 362-365, 2015.
[8] R.P.Salunkhel and A.A.Patil, "Image Processing for Mango Ripening Stage Detection: RGB and HSV method," 2015 Third International Conference on Image Infonnation Processing., no. c, pp. 362-365, 2015.

[9] H.E.Stevens, "Papaya Diseases,” no. c, pp. 57-63,1939.

[10] A. K. W. Law, H. Zhu, F. K. Lam, and F. H. Y. Chan, "Tumor Boundary Extraction in Multislice MR Brain Images using Region and Contour Deformation,” pp. 1-5, 2001.

[11] A.Ming and Huadong Ma "A blob detector in color images,"pp. 364370, 2007.

[12] M.Shaban Al-Ani and K.M.Ali Altheeti " Precision Statistical Analysis of Images Based on Brightness Distribution, " Advances in Science, Technology and Engineering Systems Journal Vol. 2, No. 4, 99-104 (2017).

[13] C. N. Dsouza, "EDGE Preserving Image Enhancement for Color and Gray Scale Images using Local Mean and Local Standard,” no. July, 2017.

[14] D. Surya Prabha and J. Satheesh Kumar, "Assessment of banana fruit maturity by image processing technique,” J. Food Sci. Technol., vol. 52, no. 3, pp. 1316-1327, 2015.

[15] P. B. Padol, "Fusion Classification Technique Used to Detect Downy and Powdery Mildew Grape Leaf Diseases," 2016 Int. Conf. Glob. Trends Signal Process. Inf. Comput. Commun., pp. 298-301, 2016.

[16] M. V Latte and S. Shidnal, "Multiple Nutrient Deficiency Detection in Paddy Leaf Images using Color and Pattern Analysis,” 2016 Int. Conf. Commun. Signal Process., pp. 1247-1250, 2016.

[17] S. Ramesh and B. Rajaram, "IoT based Crop Disease Identification System using Optimization Techniques,” ARPN J. Eng. Appl. Sci., vol. 13, no. 4, pp. 1392-1395, 2018.

[18] S. Puttemans, Y. Vanbrabant, L. Tits, and T. Goedem, "Automated visual fruit detection for harvest estimation and robotic harvesting,” pp. 1-6, 2016.

[19] R. Jain and P. K. Johari, "An Improved Approach of CBIR using Color Based HSV Quantization and Shape Based Edge Detection Algorithm,” in IEEE International Conference on Recent Trends in ELectronics Information Communication Technology, 2016, pp. 1970-1975.

[20] S. Ramesh and D. Vydeki, "Application of machine learning in detection of blast disease in South Indian rice crops,” J. Phytol., vol. 11, pp. 31-37, 2019.

[21] Z. H. Husin, N. S. A. M. Taujuddin, R. Ibrahim, and S. Sari, "Detection and Classification of Malaria Parasite using Morphological Threshold Area Estimation Technique,” J. Adv. Res. Dyn. Control Syst., vol. 12, no. Special, pp. 840-845, 2020. 